Dossiê cultura popular 


\section{Ciência e paciência: \\ o mestre Oswaldo Elias Xidieh}

ZENTR CAMPOS REIS

$\longrightarrow$

LIVE STAPLER Lewis já era um velho e conhecido ensaista e professor de literatura, quando escreveu a respeito da importância da disciplina a que se dedicou. Parecia-lhe que a literatura complementa e alarga, pela multiplicação dos pontos de vista, a experiência do real, do imaginário e do possível, forçosamente limitada, em cada ser humano isolado. E dizia: "Lamento que os bichos brutos não possam escrever livros. É com júbilo que aprenderia que cara tem o mundo para um camundongo ou para uma abelha. E é com um prazer ainda maior que perceberia o mundo olfativo, carregado de todas as informaçónes e de todas as emoçôes que ele proporciona a um cão" (1).

Importa, pela mediação da literatura, incorporar a visão e a voz do outro, que o escritor é capaz de interpretar. Os ficcionistas poderiam, por exemplo, fornecer uma imagem fiel das camadas populares, habitualmente excluídas do benefício da memória histórica. Sabemos, porém, que essa expectativa não é apenas artística: pressupõe avanço da consciência democrática, sensibilidade afinada com a dos condenados da terra.

No Brasil, tem sido lenta e penosa conquista, marcada por contratempos e longe de ser definitiva, ainda hoje. Um exemplo: José Américo de Almeida, com $A$ bagaceira, de 1928, foi um precursor do romance do Nordeste, e representou passo importante no caminho da conquista de uma consciência artística moderna e mais democrática. Leiamos o que ele declarou, em 1967, quando tomou posse na Academia Brasileira de Letras: "Acharão que falta vida interior (nas personagens de $A$ bagaceira). Não cuidei disso. Como analisar estados de consciência em seres vulgares, vazios de reflexão? Tudo era instinto e força da natureza; não havia o que revelar, se não repentes da energia material" (2).

No mínimo decepciona este juízo acerca das camadas populares, cuja linguagem está tão bem documentada naquele romance. A sabedoria popular, contida na linguagem e, muitas vezes, no silêncio, nem sempre encontra intérpretes à altura entre os letrados. A escrita, que pode unir, mais freqüentemente separa. São raros aqueles que têm ouvidos para essa fala lacunosa e para esse silêncio eloqüente (sem pretensão de paradoxo). Um exemplo: o Graciliano Ramos de 
Vidas secas. "Procurei", diz ele, "auscultar a alma do ser rude e quase primitivo que mora na zona mais recuada do sertão, observar a reação desse espírito bronco ante o mundo exterior, isto é, a hostilidade do meio físico e da injustiça humana. - Por pouco que o selvagem pense - e os meus personagens são quase selvagens o que ele pensa merece anotação. Foi essa pesquisa psicológica que procurei fazer" (3).

É significativo que muitos dos leitores de Graciliano Ramos, ainda hoje, enfatizem antes as limitaçóes do que a sabedoria prática de Fabiano e de sinha Vitória. Sinha e não sinhá, ao contrário de tantas personagens do romance e da reflexão sociológica nordestinos, mais atentos à vida das camadas senhoriais.

\section{O silêncio dos vencidos}

Foi para mim um achado a leitura de Narrativas pias populares, do professor Oswaldo Elias Xidieh, e a conversa com o Autor, num curso de pós-graduação, em 1972. Naquele tempo, vivíamos com o coração miúdo, derrotados na resistência à ditadura militar. Esta reprimia feroz o que restava de oposição a seus desmandos, e desenvolvia intensa campanha publicitária em torno de sucessos econômicos e esportivos; evocava os 150 anos da independência política do país e os 50 da Semana de Arte Moderna. As palavras mudavam de sentido, manipuladas pelo poder político-militar. Náo tinham até mesmo subvertido o significado da palavra revolução?

Refugiávamo-nos no silêncio ou na linguagem cifrada e alusiva do escravo Esopo, coagido à meia palavra da fábula. $\mathrm{O}$ momento ajudava na compreensão da cultura dos herdeiros diretos do fabulista grego: as camadas populares. $\mathrm{Na}$ época, eu pelo menos não sabia disso com clareza.

O livro do professor Xidieh ajudava muito: naquelas narrativas, que ele soube ouvir e interpretar, expressavam-se aspiraçóes de justiça, de igualdade, de esperança, que eram as das camadas populares e eram as nossas. Vinham de longe: lidas por ele, a longa história da opressão ressurgia, combinada com a admirável lição de paciência histórica dos oprimidos, absurda para a urgência da juventude militante daqueles e talvez de todos os tempos.

Também o estudante de literatura brasileira sentia-se menos inseguro: quem lida com essa disciplina carece de apoios na realidade, já que a ficção é seu objeto preferencial. $O$ real, acredita, está melhor representado pela sociologia, pela antropologia e pela história. Desejávamos o apoio da ciência, capaz de apreender o sumo do acontecimento, expressá-lo de forma precisa, com a indispensável abstração, mais pobre que o real imediato, porém mais rica como produto de elaboração científica. 
As narrativas populares ensinavam outro modo de articular idéias abstratas e valores: o modo narrativo. A narrativa é uma das formas que assume a sabedoria popular, talvez a principal. Combina real e possível, miséria e dignidade humana, precariedade presente e desejo utópico de um futuro mais justo, assim na terra como no céu.

\section{Vozes da fala popular}

Mas é preciso saber lê-la, em sua linearidade e em suas estratificações. A narrativa é síntese de muitas vozes, ensina mestre Xidieh. E de muitos tempos: os vestígios dissimulam-se na linguagem compósita, no compósito elenco de personagens e na caracterização de espaços e objetos. Leiam-se as finas análises de indícios do processo de urbanização, em convívio tenso com antigas formas de sociabilidade, presentes em algumas estórias: "Pouso em casa de rico deve ser a [narrativa] que mais se aproxima de algum modelo mais antigo e no qual, em lugar de homem rico, devia haver um rei ou um fazendeiro. Aliás, nas em que o homem ruim era um rei. Contudo, conserva ela traços tipicamente rústicos, como linguagem, personagens extra (o escravo), material ergológico (chicote de nervo de boi)" (4).

Em $A$ promessa, trabalho que integra o estudo da Semana Santa cabocla, as interjeiçōes barbaridade, beco [/é/], uai, indicam a presença de gaúchos e caipiras paulistas e mineiros, no auditório do narrador, o "venerável bandeireiro do Tietê", em Pilar do Sul (5).

A síntese narrativa, que compreende personagens, ambientes, indicaçôes temporais e linguagem, exprime exemplarmente a integração do heterogêneo, que parece a vocação da cultura popular. Uma integração em vista da operacionalidade, conforme explica o professor Xidieh: "A literatura popular não é gratuita, como não são gratuitos todos os seres e coisas que integram o mundo rústico. Em nenhuma outra sociedade, a não ser entre aquelas denominadas primitivas, a cultura se define, como na sociedade cabocla em termos de estrita utilidade. Ali, o que não é útil, isto é, não aplicável a alguma coisa, não tem nome, não existe ou se classifica como 'imundície do mato' ou tolice 'sem fundamento'. Fauna e flora emergem naquela cultura como animais e madeiras, insetos e plantas com os quais determinados trabalhos e objetos podem ser feitos ou que dão alguma coisa. Qualquer elaboração oral por mais que pareça simples divertimento encerra sempre algo de utilidade, de preceito e de etiqueta" (6).

É necessário cautela: o que parece sem fundamento pode indicar apenas insuficiência do entendimento humano, como no belo conto O Pecado e a Morte: 
"Certa vez, no tempo em que Jesus e o apóstolo Pedro andavam pelo mundo, aconteceu que eles chegaram à beira de um grotão coberto de mato. Fazia muito calor e Jesus disse:

'- Olha aqui, São Pedro, vamos descansar um pouco, mas, antes, desça na barroca e procure água pra gente beber.'

São Pedro foi e, no meio da descida, topou com uma velha que estava pelejando para pôr no ombro um feixe de lenha. $O$ feixe era grande e pesado e a velha não conseguia erguê-lo. A velha punha o feixe no chão, desatava o amarrilho e, em lugar de tirar algumas lascas de lenha, juntava mais ainda. Pedro, espantado, ficou um tempo vendo aquele disparate. E não adiantava chamar a atençáo da velha. Ela era surda.

Pedro viu que no mundo há muita coisa sem fundamento, sacudiu o ombro e continuou a descer pela pirambeira. Lá em baixo tinha um homem que batia com uma vara muito comprida numa árvore carregada de botóes de flores, de frutas verdes, de frutas maduras, de frutas temporãs e de frutas podres. $\mathrm{E}$ derrubava de tudo. Pedro ficou brabo e gritou com o homem, mas o homem era surdo e cego. Pedro desanimou e foi encher a guampa no ribeirão, e, quando voltou ao lado de Jesus, contou-lhe o que tinha visto.

Jesus, rindo que dava gosto a gente ver, explicou tudo para São Pedro. A mulher surda e velha que pelejava com a mucuta, era o Pecado; o homem surdo e cego, derriçando a árvore, era a Morte. O Pecado é surdo e nunca está contente, quando mais desanda mais fácil the parece aumentar a carga de ruindades. A Morte é surda e cega, não sabe e não pode afastar-se do lado da Vida e, por isso, derruba, sem saber e sem ver, flores e frutas" (7).

Jesus e Pedro, nesta e nas demais narrativas transcritas no livro, descem à Terra, longe da majestade do catolicismo oficial, e tipificam as figuras do mestre e do discípulo. A limitação e as fraquezas muitas vezes patéticas do discípulo são as da humanidade: cada ouvinte ou leitor sente-se solidário e identificado com Pedro.

Chama a atenção o fato de o Pecado surgir, no conto, na figura de mulher, e a Morte, na de homem, contrariando a iconografia habitual. Colhida em São Paulo, pode tratar-se de narrativa de origem germânica: em alemão, Morte é masculino, Der Tod; Pecado, feminino, Die Siinde (8). Será talvez vestígio de tradução, acolhida e divulgada oralmente. 
Xidieh desenha sobo ditado de João Pico, em Jacarei (1950), as figuras de Pedro e Jesus imaginadas pelo informante

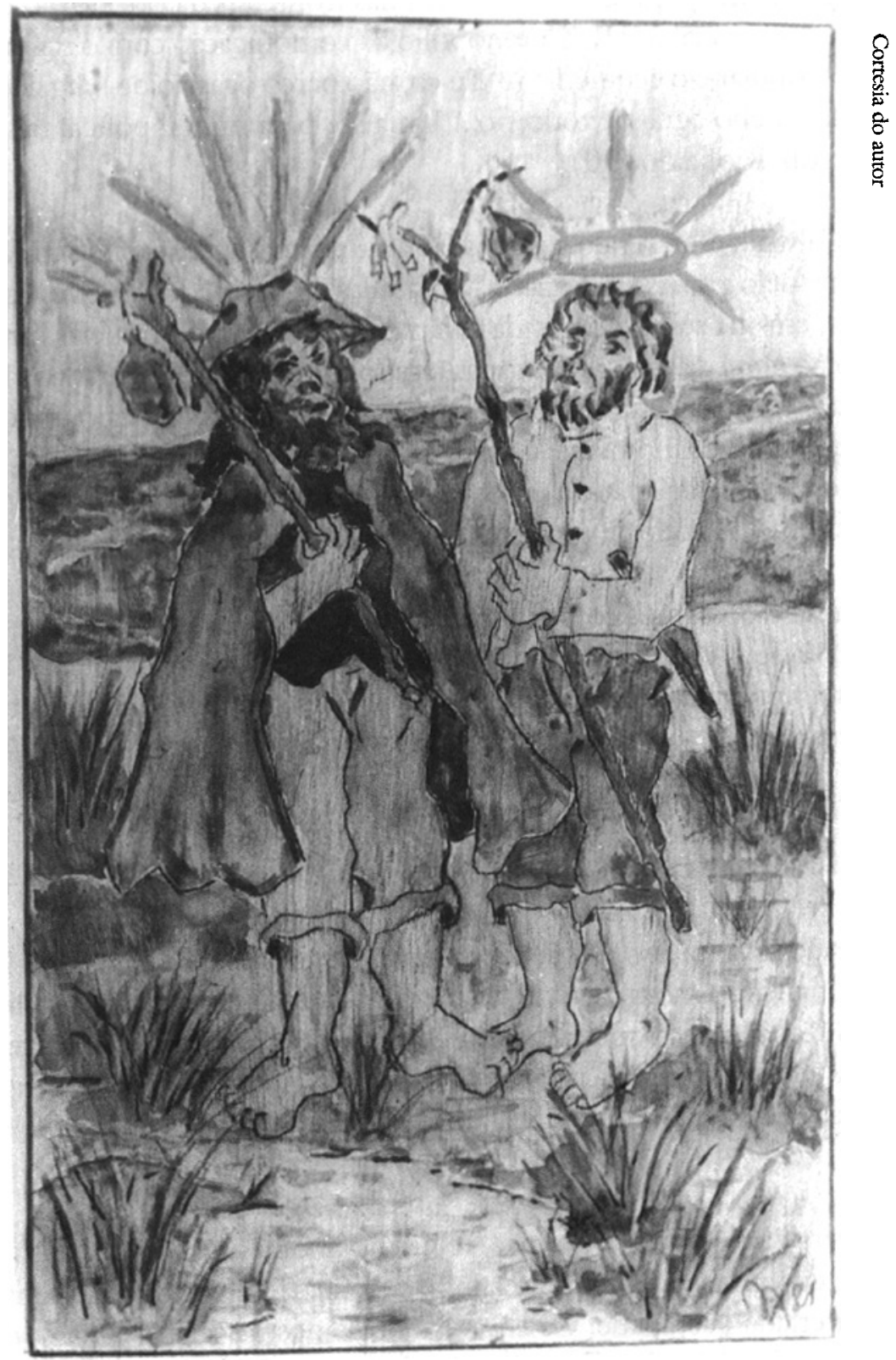

Assim como acolhe as contribuições estratificadas de vários tempos, a cultura popular não conhece fronteiras. Exemplar, nesse sentido, o ensaio Um elemento italo-afro-brasileiro na magia mogiana, que narra o itinerário de José Zarrelli, servente de pedreiro, pastor e auxiliar de jardinagem num convento em Salerno. Já no Brasil, em Santo Ângelo, comercializa produtos agrícolas, primeiro adquiridos no mercado, depois produzidos por ele mesmo, em pequena propriedade. Torna-se entalhador, assiste ao aproveitamento de suas estatuetas na magia e vira, ele próprio, benzedor-feiticeiro (9).' 
A religiosidade popular não se detém nas fronteiras da ortodoxia. Nenhuma religião confessional detém o monopólio da comunicação com o sagrado: é o pensamento popular e o ecumênico. "Eu cá, não perco ocasião de religião. Aproveito de todas. Bebo água de todo rio... Uma só, para mim é pouca, talvez não me chegue", diz Riobaldo (10).

Italo Calvino, escrevendo sobre as fábulas italianas, parece referir-se às estórias estudadas pelo professor Xidieh: "as fábulas são verdadeiras. São, tomadas em conjunto, em sua sempre repetida e variada casuística de vivências humanas, uma explicação geral da vida, nascida em tempos remotos e alimentada pela lenta ruminação das consciências camponesas até nossos dias; são o catálogo do destino que pode caber a um homem e a uma mulher". Vê naquelas narrativas, sobretudo, a percepção da "substância unitária do todo: homens animais plantas coisas, a infinita possibilidade de metamorfose do que existe" (11).

Quem sabe possamos colher aí uma indicação para compreender a unidade, universalidade e coerência, a concordia discors, da cultura popular? É uma cultura que tem passado e terá futuro, enquanto persistirem as condiçóes que lhe deram origem: a cisão da sociedade entre os que mandam e os que trabalham (12).

\section{Sujeito, objeto}

A reflexão do professor Xidieh tem também passado: a infância em Pilar e Taquaritinga, ouvindo mestre Colodino, retireiro, e mãe Domingas; a militância política em Suzano, com os mestres trabalhadores; a formação filosófica, na antiga Faculdade de Filosofia, Ciências e Letras, com mestre Charles Maugüé; a formação sociológica e antropológica, com os mestres Roger Bastide e Emilio Willems.

A universidade, no entanto, não se harmonizou com a vivência popular: "O que é que eu vim fazer aqui?", exclamou perplexo, em 1938, quando ingressou na recém-criada Faculdade. Os ensaios publicados na revista Sociologia (13) ressentem-se da duplicidade que então se criou: o sociólogo descolado do seu objeto, descrevendo escrupulosamente as práticas populares e tentando compreendê-las com o instrumental fornecido pela ciência acadêmica. Sente-se, porém, a empatia profunda do pesquisador: o escrúpulo não é apenas exigência acadêmica, mas cumplicidade, talvez o receio de trair uma experiência que, no fundo, era sua. O ouvinte e sociólogo Oswaldo Elias Xidieh consegue transformar palavras, se não em coisas, pelo menos em imagens: desenha sob ditado de João Pico, em Jacareí, no ano de 1950, as figuras de Jesus e Pedro imaginadas pelo informante. 


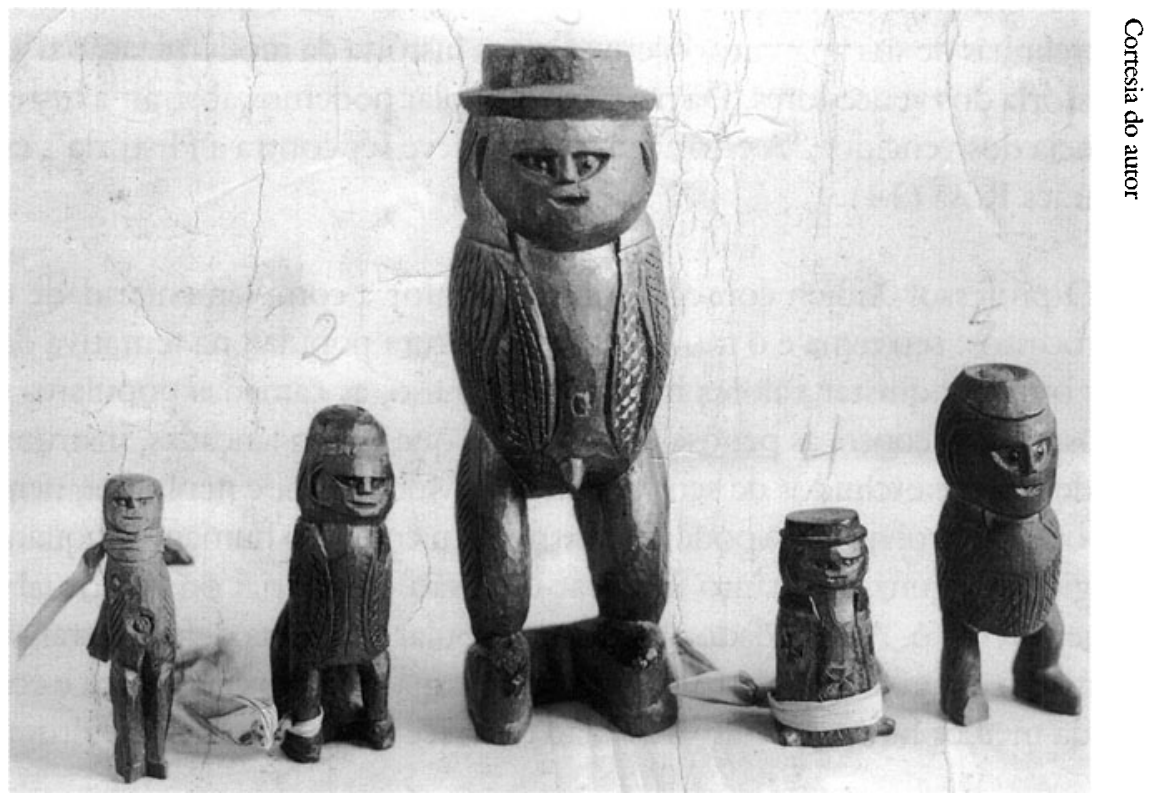

Imagens talhadas por José Zarelli em Santo Angelo (1939-40) e usadas em trabalho de macumba

Não foi sem trabalho e sofrimento que conseguiu integrar contribuições tão heterogêneas. Parece ter sido uma longa anamnese, que resultou no belo ensaio Da Semana Santa e das muiltiplas paixōes (FSP, 17 abr. 1987), no qual expóe, como em retábulo, os passos, as estações das vias sacra e profana, que acompanhou ou de que foi protagonista. Paixão tem aí o sentido forte e preciso de sofrimento, o que Cristo padeceu na cruz, mas se estende, abrangendo aquela reconquista dolorida e feliz da infância pela memória. Agora, sujeito e objeto se reaproximam: o sujeito percebe outros sujeitos, onde ele via objetos. Mais do que isso, reconhece-se altivo um deles.

Tinha chegado o momento de reabilitar as liçóes de mestre Colodino, agudo observador de uma natureza sempre em movimento, sempre variável, como as muitas águas de um rio: "de hora em hora Deus melhora"; atento aos temperamentos e caracteres, ciente dos lastros da natureza, que é necessário respeitar, e da possibilidade de intervenção humana sobre ela.

A memória da escravidão, viva em mãe Domingas, a língua arcaica de que se servia, ensinava essa convivência dos tempos históricos, que os adeptos da modernidade não enxergam ou se negam a ver, isto é, a levar em conta.

Tínhamos dito que a narrativa popular, síntese de tantas outras práticas, contém subjacente a sabedoria prática do povo. Paralelamente, e em sentido inverso, pode-se dizer que a exposição abstrata da ciência também comporta uma narratividade implícita. 
Na verdade, a diferença reside em que a ciência, mais amiúde, contrabandeia, nas entrelinhas de sua aparente objetividade, a história da modernização triunfante, a história dos vencedores. Da narrativa popular podemos abstrair a história da resistência dos vencidos. "A estória, em rigor, deve ser contra a História", escreve Guimarães Rosa (14).

O professor Xidieh consegue nos transmitir a complementaridade desses dois processos: seu tema é o movimento da cultura popular, na tentativa de conquistar ou reconquistar valores humanos. A pulso, as camadas populares resgatam-nos, na lida contra as penosas condiçóes a que foram lançadas, instrumentos da modernidade excluídos de seus benefícios. Modernidade nenhuma, nem progresso ou desenvolvimento poderá construir um convívio humano, enquanto for privilégio de alguns, enquanto implicar exclusão - material ou espiritual - sob qualquer pretexto. A vitalidade da cultura popular reside na defesa intransigente do princípio da igualdade entre os viventes, na sua vocação ecumênica e ecológica. Nada merece tanto ser cultivado, nada merece tanto o nome de cultura.

\section{Notas}

1 C.S. Lewis, Expérience de critique littéraire. Trad. par Jean Autret (c. Lagny-sur-Marne) Gallimard, 1965 , p. 203.

2 José Américo de Almeida, Discurso de posse, pronunciado na Academia Brasileira de Letras, 28 junho 1967, em: A bagaceira. Rio de Janeiro, José Olympio, 1978, p. 238.

3 Graciliano Ramos, apud Clara Ramos. Mestre Graciliano. Confirmação humana de uma obra. Rio de Janeiro, Civilização Brasileira, 1979, p. 125.

4 Oswaldo Elias Xidieh, Narrativas pias populares. Estórias de Nosso Senhor Jesus Cristo e mais São Pedro andando pelo mundo. (Belo Horizonte) Itatiaia, 1993, p. 120.

5 Oswaldo Elias Xidieh. Semana Santa cabocla. São Paulo, IEB, 1972, p. 34.

6 Xidieh, Narrativas..., cit., p. 26.

7 Idem, ibidem, p. 61.

8 Agradeço a ajuda lingüística de Ilma Esperança de A. S. Curti.

9 Publicado em Sociologia, 1944.

10 João Guimarães Rosa. Grande sertão: peredas. 3. ed., Rio de Janeiro, José Olympio, 1963.

11 Italo Calvino, Fábulas italianas. (Colctadas na tradição popular durante os últimos cem anos e transcritas a partir de diferentes dialetos). 2. imp. Trad. de Nelson Moulin. São Paulo, Companhia das Letras, 1993, p. 14-15. (Edição integral italiana, 1956; Seleta, 1968).

12 Termos utilizados por José de Souza Martins, em Subrirbio. Vida cotidiana e história no subúrbio da cidade de São Paulo: São Caetano, do fim do Império ao fim da República Velha. São Paulo, Hucitec, 1992. (Introdução: Por uma compreensão do esquecimento e do silêncio, p. 7-23). 
13 Elementos Mágicos no folk mogiano, Um elemento ítalo-afro-brasileiro na magia mogiana e O intermediário, publicados em 1943, 1944 e 1945, respectivamente.

14 João Guimarães Rosa, Aletria e hermenêutica, em: Tutaméia. Terceiras estórias. Rio de Janeiro, José Olympio, 1967, p. 3.

\section{Bibliografia de Oswaldo Elias Xidieh}

Artigos:

O Estado de S. Paulo

A montanha e a floresta, 12 e 19 abr. 1945.

Estrelas, homens e preconceito, 14 e 19 maio 1948.

Semana Santa Cabocla:

I. Generalidades, 16 jun. 1948;

II. Elementos mágico-religiosos, 28 jul. 1948;

III. O culto das almas, 13 ago. 1948;

IV. A promessa, 19 jan. 1949).

Resenha folclórica, 3 set. 1948.

Mboy-tatá, 17 dez. 1948.

Benzimentos, 16 fev. 1949.

Rezas bravas, 14-jul.1949.

Simpatias contra doenças. 14 mar. 1949

(Esses artigos, acrescidos de Subúrbio, publicado em 1947, na Revista do Arquivo Municipal, compóem o volume Semana Santa Cabocla. Rezas bravas foi ampliado para essa publicação.

\section{Sociologia}

Elementos mágicos no folk mogiano. Sociologia, São Paulo, v. 5, n. 2, p. 116-133, 1943.

Um elemento ítalo-afro-brasileiro na magia. Sociologia, São Paulo v. 6, n. 1, p. 1-14, 1944.

O intermediário. Sociologia, São Paulo, v. 7, n. 1-2, p. 11-29, 1945.

\section{Repista do Arquipo Municipal}

Subúrbio. Rerista do Arquivo Municipal. São Paulo, n. 114, p. 173-184, 1947.

\section{Anbembi}

Relaçôes raciais entre negros e brancos em São Paulo. Anbembi, São Paulo, v. 18, n. 54, p. 487$502,1955$.

Folha de S. Paulo

Da Semana Santa e das múltiplas paixōes. Folha de S. Paulo, São Paulo, 17 abr. 1987. 
Livros:

Narrativas pias populares. São Paulo, Instituto de Estudos Brasileiros, 1967.

Semana Santa cabocla. São Paulo, Instituto de Estudos Brasileiros, 1972.

Traduções:

BALANDIER, Georges. Antropológicas. Trad. Oswaldo Elias Xidieh. São Paulo, Cultrix-Edusp, 1977.

HUGO, Victor. Em viagem, 3 v., trad. Oswaldo Elias Xidieh, o terceiro em colaboração com Jamil de Almansur Haddad, em: Obras completas, V. 32 a 35. São Paulo, Edameris, 1959.

SPERBER, Dan. Osimbolismo em geral. Trad. Frederico Pessoa de Barros e Oswaldo Elias Xidieh. São Paulo, Cultrix, 1978.

\section{Bibliografia consultada (citada ou não):}

ALMEIDA, José Américo de. A bagaceira. Rio de Janeiro, José Olympio, 1978.

ARROYO, Leonardo. A cultura popular em Grande sertão: veredas (Filiaçóes e sobrevivências tradicionais, algumas vezes eruditas). Rio de Janeiro, José Olympio, 1984.

BASTIDE, Roger. As religiōes africanas no Brasil. Contribuição a uma sociologia das interpenetraçóes de civilizaçóes. Trad. de Maria Eloisa Capellato e Olívia Krähenbühl. 2 v. São Paulo, Pioneira, 1971.

BEZERRA, Aída \& BRANDÃO, Carlos Rodrigues (org.). A questão política da educação popular. São Paulo, Brasiliense, 1980.

BOSI, Alfredo. Cultura como tradição, em BORNHEIM, Gerd e outros. Tradiçāo contradição. Rio de Janeiro, Zahar, 1987, p. 31-58.

Dialética da colonização. Sáo Paulo, Companhia das Letras, 1992.

CALVINO, Italo. Fábulas italianas. (Coletadas na tradição popular durante os últimos cem anos e transcritas a partir de diferentes dialetos). 2. imp. Trad. Nelson Moulin. São Paulo, Companhia das Letras, 1993. (Edição integral italiana, 1956; Seleta, 1968).

CANDIDO, Antonio. Os parceiros do Rio Bonito. Estudo sobre o caipira paulista e a transformação dos seus meios de vida. Rio de Janeiro, José Olympio, 1964.

FERNANDES, Florestan. O folclore em questão. São Paulo, Hucitec, 1978 (Coleção Estudos Brasileiros, 8).

Folclore e mudança social na cidade de São Paulo. Petrópolis, Vozes, 1979.

GÓRKI, Máximo. Ganhando meu pão. Trad. e apresentaçăo de Bóris Schnaiderman. São Paulo, Brasiliense, 1986. 
GRAMSCI, Antonio. Obras escolhidas. Trad. Manuel Cruz. Lisboa, Editorial Estampa, 1974.

LEWIS, C. S. Expérience de critique littéraire. Trad. Jean Autret (c. Lagny-sur-Marne), Gallimard, 1965.

MARTINS, José de Souza. Subuirbio. Vida cotidiana c história no subúrbio da cidade de São Paulo: São Caetano, do fim do Império ao fim da República Velha. São Paulo, Hucitec, 1992. (Introdução: Por uma compreensão do esquecimento e do silêncio, p. 7-23).

PIERSON, Donald. Cruz das Almas. Com a colaboração de Carlos Borges Teixeira, Levy Cruz, Mirtes Brandão Lopes, Helen Batchelor Pierson e outros. Rio de Janeiro, José Olympio, 1956.

RAMOS, Clara. Mestre Graciliano. Confirmação humana de uma obra. Rio de Janeiro, Civilização Brasileira, 1979.

ROSA, João Guimarães. Grande sertâo: veredas. 3. ed., Rio de Janeiro, José Olympio, 1963.

- Tutaméia. Terceiras estórias. Rio de Janeiro, José Olympio, 1967.

SATRIANI, Luigi M. Lombardi. Il silenzio, la memoria e lo sguardo. Palermo, Sellerio editore, 1980.

WILLEMS, Emílio. Uma vila brasileira. Tradição e transição. Prefácio de Nelson Werneck Sodré. São Paulo, Difel, 1961.

Zenir Campos Reis é professor de Literatura Brasileira na Faculdade de Filosofia, Letras e Ciências Humanas da USP. 